\section{THE POLITICS OF DISCOURSE IN SEXUAL ABUSE NARRATIVES}

\section{Chutima Pragatwutisarn ${ }^{1}$}

\begin{abstract}
Although sex is considered something private and personal, telling sexual stories is by no means a personal matter. The difficulty faced by sexual abuse victims who want to tell their stories is due to the ways in which the meanings of sexual abuse, the abuser and the victim are discursively constructed by the dominant culture. As a result, a tension between the individual desire to tell stories and the social injunction to silence is invariably found in women's narratives of sexual abuse. This paper explores how discourses of the dominant culture discourage women from breaking their silence about sexual abuse and how the emerging voices of sex abuse victims have led to the reevaluation of discourses, power, and female subjectivity. My discussion will be divided into two parts: the first part-'Talking Back'-will focus on sexual abuse narratives written by female survivors' and the second part -'Public Confession' - will examine survivors discourse broadcast in television programmes.
\end{abstract}

\footnotetext{
${ }^{1}$ Lecturer, Department of Comparative Literature, Faculty of Arts, Chulalongkorn University
}

And if I persisted in this notion that bodies were in some way constructed, perhaps I really thought that words alone had the power to craft bodies from their own linguistic substance. -- Judith Butler, Bodies That Matter

In silence secrets turn to lies. Secrets are sacred truths - the Self, unshared becomes dead silence. -Terry Wolverton, Voices in the Night

I never saw anyone like me in the incest books. I never saw anyone who said she had a good relationship with her father. All the perpetrators looked like angry, ugly, mean people, and yet my father appeared to be a loving charming wonderful man. I loved and adored him. He treasured me. That made the whole thing even more insidious. My story needs to be told because women need to know their experience counts. There is no such thing as mild abuse. -- Randy Taylor, The Courage to Heal

\section{Introduction}

The postmodern view of the constituting capacity of language sheds a new light on the notion of subject. That is, there is no subject outside or beyond the symbolic system of language. The subject, always already mediated by a discourse of language, has a genealogy that accounts for how it comes into being. The constituting power of language deconstructs the traditional distinction between the real and 
the unreal. It is not that language is seen as a transparent medium that comes to represent extra-linguistic reality but rather that it is language and rhetorical strategies that construct what we come to know as reality. The discovery that the real itself is an effect of rhetorical strategies undermines the stability of a discourse that claims its truth to be universal, absolute and transcendental. Instead it allows us to see a connection between the issue of politics and the linguistic construction of the subject. That is, the control of discourse, of producing or withholding particular forms of knowledge, is also a political control precisely because it is a control of what 'is,' of cultural ideological representations that come to be known as truth or reality.

This paper will focus on how the politics of discourse exercises its power over the female body and female subjectivity. Using narratives of sexual abuse told by female survivors as case studies, I want to argue that there appears in these narratives a site of political control over the female subject through the discourse of language and the possibility of subverting that control. The relationship between the female victim and the male abuser is a discursive one in which the latter imposes silence upon the former. What is more important is that the injunction to silence is perpetrated and validated by public discourses such as taboos, social values, and legal systems. Such discursive forms discourage women from speaking out about their experience of sexual abuse by regarding the issue as unspeakable, inconceivable or unimportant. The narratives of sexual abuse, like those told by victims of race, gender and class prejudice, are known as marginal discourses subsumed and suppressed under the public discourse of the dominant culture. Excluded from the cultural realm and its production of meaning, the narratives of sexual abuse remain unknown and unlistened-to stories.

Only recently have women begun to break their silence and tell their experiences of sexual abuse from their own points of view. A simple act of telling for these female survivors is revolutionary not only because it has never happened before but also because it is a challenge to the dominant culture and its injunction to silence, a revision of such concepts as discourse, power and female subjectivity. Women's stories of sexual abuse illustrate a subject who is not passively derived from the discourse of language. The survivor who breaks the silence plays the role of a resisting subject who refuses to be placed as powerless in the dominant discourse and constitutes her own narrative to give voice to her experience. The survivor thus uses language as a strategic means of changing her subject position from victim to victor, from powerlessness to self-empowerment.

My discussion of the politics of discourse in sexual abuse narratives told by female survivors will be divided into two parts. The first part — 'Talking Back' - will focus on sexual abuse narratives written by female survivors and the second part — 'Public Confession' - will examine the survivor discourses broadcast in television programmes. The arrangement of my paper into two parts illustrates my attempt to deconstruct the monologic discourse of traditional narrative that privileges a single voice of the autonomous, coherent, universal subject. The juxtaposition of the two 
sections forms a dialogic discourse in which no one voice is privileged over others. Also, in my discussion, I do not limit myself to one specific theory but borrow from various sources such as personal experience, memory, social and literary theories. While many theoretical concepts are useful to my analysis of the politics of discourse in sexual abuse narratives, by putting theories together with the survivors' experiences, I expose the limitations of some of these theories and hope to advance the issue of the politics of discourse in my discussion.

\section{Talking Back}

When the survivors' narratives enter the public realm which attempts to deny their existence, we might expect a tension between the established discourse of the dominant culture and the marginal discourse of the female survivors. In this section, I explore how the stabilization of the dominant culture and the forces that push against it are played out in sexual abuse narratives. I want to argue that the disruption of established boundaries (i.e. inside vs outside, private vs public) by the marginal discourse of female survivors will open the way to our rethinking of discourse, power and construction of female subjectivity.

I have found Michael Ryan's discussion of how a modernist discourse of liberalism uses its rhetorical strategies to maintain its power useful in my analysis of sexual abuse narratives. Ryan's critique of liberalism focuses on the modernist theory of representation in which the sign system has come to represent extra-linguistic reality. Postmodernism, Ryan argues, rejects this epistemological framework by regarding such concepts as truth and reality as the effects of rhetorical strategies. Therefore, the postmodern view of representation creates a reversal of sign and thing, of image and reality: 'Rather than being expressive representations of a substance taken to be prior, cultural signs become instead active agents in themselves, creating and evoking new substances, new social forms, new ways of acting and thinking, new attitudes, reshuffling the cards of 'fate' and nature' and 'social reality" (Ryan, 1989: 83). The discovery that a modernist discourse of liberalism also depends on rhetorical strategies to construct reality undermines the stability of its truth claim which has been considered unquestionable, absolute and transcendental. It is at this point that the production of knowledge through a discourse of language becomes a political issue. The fabrication or suppression of certain knowledge through discourses is in order to maintain the stability of the dominant culture. Ryan discusses how liberalism uses strategies to construct its ideality by suppressing other discourses:

$[\ldots]$ the more it strove to transcend its practical side, the more evident it became that liberalism had to be a fairly sophisticated exercise of rhetoric, a very practical system of subordination and displacement, of condensation and substitution, if it was to justify capitalism (Ryan, 1989: 135).

Liberalism uses its rhetorical strategies to promote the capitalistic mode of living. The stabilization of power by rhetorical strategies makes it become necessary for 
some discourses of knowledge to be constructed at the expense of the others.

Ryan's discussion of the political control of knowledge can be applied to the issue of sexual abuse. A theoretical discourse, constructed to explain or deny the existence of sexual abuse, has a political function aiming to maintain the stability of the dominant culture. Such is the case of Freud's psychoanalytic theories and his silence about the problem of sexual abuse. According to Vera Gallagher, Freud discovered from his female patients that hysteria had its root in their sexual relations with male relatives in their families. However, Freud was hesitant to report his discovery because it would expose the fact that 'incest was not an offence relegated to the poor and the criminal members of society but a fact of life in the established patriarchal family' (Gallagher, 1985: 27). Realizing that his findings would jeopardize middle class values and his own reputation, Freud, in his account of hysteria, buried women's stories of incest in the Oedipal theory. Gallagher says, 'Freud took the easier way out and announced that his patients longed for and therefore fantasized about sexual encounters with fathers and male relatives. Blaming the women was easier than believing them' (Gallagher, 1985: 27). Women's stories of sexual abuse embedded in public discourses such as Freud's theories are subject to misinterpretation and distortion. The recuperation of women's narratives, as in Freud's psychological theories, is a way of neutralizing their threatening force against the established values of the dominant culture.
Ryan's discussion of the privileging of the ideal over actuality in the modernist discourse of liberalism is important in understanding why silence about sexual abuse is maintained, if not enforced, by society. According to Ryan, the privilege of equality as the ideal of liberal society reduces the problem of inequalities to 'secondary accidents' and even regards the problem as a threat to the ideal. Ryan describes how the binary opposition of ideal/actuality, inherent in the modernist concept of rationalism, simply ignores rather than solves the problem of inequalities: 'It has often been noted that rationalism results in ideology, a discrepancy between the ideal and actuality, because rationalist ideals are belied by material inequalities that are stabilized [...] by those ideals' (Ryan, 1989: 200).

Similar to the problem of inequalities discussed by Ryan, the silence about sexual abuse is caused by society's emphasis on its ideal. The goal of socio-ideological values is to maintain the stability of society. In 'Ideology and Ideological State Apparatus,' Louis Althusser describes how ideology as a system of representations operates to maintain social stability by suturing any seams and smoothing over any differences or contradictions and promoting on the part of the subject an 'imaginary' relation to the 'real' conditions of its existence (qtd. in Silverman, 1983: 215). The 'imaginary' the subject is forced to live out creates a gap between the ideal and actuality. As in the issue of inequalities, the privileging of the ideological values over lived experiences causes society to ignore the existence of sexual abuse and regards its appearance as a threat to those values. In Speaking out, 
Fighting Back, Gallagher discusses social attitudes toward incest:

Cultural barriers have long been created against incest and primitive tribes often enforce strict taboos against it. When incest is considered to be a sin, it becomes closely guarded as family secret. Denying that sexual abuse within a family could take place, or could have occurred in a family we know, or could be happening in our neighbourhood, helps each of us to maintain our own integrity. It enables us also to continue to believe in the basic goodness of humanity. (Gallagher, 1985: 25).

In public discourse, the problem of incest has been suppressed, denied or reinterpreted so that it will no longer threaten the established social values that maintain the stability of society. Therefore, incest is interpreted by society as a 'sin' and consequently put into negative opposition to the 'goodness of humanity' that society needs to promote.

The emergence of women's sexual abuse narratives that have been embedded and silenced in the public realm has thus created a tension between the dominant discourse that tries to suppress it and the marginal discourse of these women who refuse to be silenced. The tension is well illustrated by Ellen Bass and Laura Davis in their Introduction to 'Courageous Women'-a section dealing with the autobiographical narratives of sexual abuse told by women. The female survivors who contribute their stories in this section are divided into two groups: those who choose to use pseudonyms and those who want to use their own names. According to Bass and Davis, the second group of survivors wants to assert their own authority by taking responsibility for their narratives. Refusing to live their lives through the 'lies' constructed by the others, they choose 'to tell their story honestly-to name themselves, their abuser, the place where their lived, the facts of their lives' (Bass and Davis, 1988: 358). However, the attempt of these women to speak out, to use language for empowerment by turning themselves from the silent subject into the speaking subject, is frustrated by the dominant discourse of the legal system. Bass and Davis, as co-editors of the book, comment on the issue:

We wanted each woman's participation to be an empowering experience for her. However, we learned that it was not legally possible for a publisher to print a survivor's story with actual names and places if the abuser (and possibly other family members) were alive and identifiable.

This situation perpetuates the very hiding and silence that we are working to end. To tell women that they can't speak out, name their abuse and their abuser, and tell their stories in their own names without fear adds to the already formidable obstacles that women must overcome to break the silence (Bass and Davis, 1988: 358). 
For a woman to tell her personal experiences of sexual abuse, she needs to do so against the social injunction that forces her into silence. It is at that very moment of breaking the silence that a simple act of speaking about a private issue turns out to be politically significant. Such realization allows us to revise the survivor discourse which has been regarded by culture as a personal and therefore insignificant form of narrative, irrelevant to the political agenda of the public realm.

In Politics and Culture, Ryan argues that the division between inside and outside, public and private is an effect of the rhetorical strategies of the modernist discourse of liberalism to maintain its dominant status. Inherent in the discourse is the concept of rationality. About this concept Ryan writes:

this rationality was formal and ideal, universal and transcendental, rather than democratic and material, or substantial and egalitarian. It privileged logic over rhetoric, and it guaranteed rights only in a formal or abstract sense, not in a realized material one (Ryan, 1989: 134).

The discourse of liberalism cannot defend itself within the world of context, of relations and contradictions resulting from the juxtaposition of various discourses. As such it must establish its ideal by transcending those contradictions and differences that are threatening its stability. The discourse of liberalism must depend on rationality as the ideology to guarantee that stability. As Ryan points out, the rationality of the modernist tradition forms a binary opposition between the ideal and actuality, the universal transcendental world and the material world of context. In effect, a gap between outside and inside, public and private, is created within this binary opposition in which the second component is subordinated to the first one.

Breaking silence disrupts the binary opposition of the metaphysical tradition inherited by rational society. Since the goal of the ideal is to transcend actuality, the problem of sexual abuse is ignored when the former is privileged over the latter. By placing experience before ideality (i.e. theories, social values), the survivors acknowledge that sexual abuse is an actual fact in society that needs to be solved. In Voice in the Night, Toni McNaron and Yarrow Morgan, illustrate how the reversal makes it possible to see the issue of sexual abuse in a new light. McNaron and Morgan argue, 'Instead of looking at incest as an aberration from the norm, we need to question its place and purpose within that norm. We believe that there is no taboo against incest, merely speaking about it' (McNaron and Morgan, 1982: 15). The interpretation of incest as an aberration from the norm is meant to neutralize its threatening impact on social stability. By acknowledging the 'actuality' of incest, we no longer regard it as a taboo but a serious problem that needs to be solved.

However, the deconstruction of the binary opposition does not mean that the personal is a substitute for the theoretical. In Talking Back, bell hooks reminds us of danger in the slogan 'The personal is political' when the self is established as grounds for all kinds of reality. hooks says, 'To take woman to the 
self as the starting point for politicization, woman who is particularly made, socially constructed, to think only me - my body I constitute a universe - all that truly matters. To take her - this woman - to the self as the starting point for politicization is necessarily risky' (hooks, 1989: 105). The self limited to the private sphere loses its political efficacy to initiate a social change. hooks also comments on the issue:

The personal most know as the private, as that space where there is no intervention from the outside, as that which can be kept to the self, as that which does not extend beyond... We see now the danger. 'The personal is political.' No sense of connection between one's personal and a larger material reality - no sense of what the political is. In this phrase, what most resonates is the world personal - not the world political (hooks, 1989: 106).

Therefore, a move from 'the self as a starting point' to 'the awareness of a collective reality' is necessary if we are to escape from a narcissistic mode of thinking that depoliticizes the notion of the self and reality.

In narratives of incest, for example, McNaron and Morgan do not ground the concept of truth and reality in the self but rather put the self in the outside world of context. They historicize their experience of silence about incest in the following:

if we begin to speak of incest, we may realize its place as a training ground for female children to regard themselves as inferior objects to be used by men, as training that females cannot trust other females (our mothers didn't stop the behaviours and often passively acquiesced). Incest is an early and very effective behavioural training in powerlessness and subservience. By beginning to speak about it, we begin to threaten its continued, unacknowledged presence (McNaron and Morgan, 1982: 15).

For McNaron and Morgan, the primacy of the self does not replace the outside world of context. In their analysis of the personal experiences of incest, the two realms of public and private are not separated but put together. They do not interpret the personal in a narcissistic way as the centre of all truth and knowledge but move from the personal to the world outside in naming the self as the site of politicization. It is in the incest, they insist, that we witness how patriarchy exercises its power on the local level. By linking personal experience with reality, McNaron and Morgan avoid having these narratives reduced to personal matters. On the other hand, their emphasis on the primacy of experience over theory, the actuality over the ideal, illustrates that any social change must begin first and foremost with our self-awareness and responsibility for our own body.

\section{Public Confession}

This section will discuss survivor discourses broadcast in television talk shows such as 'Phil Donahue,' 'Geraldo,' and 'Oprah Winfrey.' I have already noted how the dominant culture uses its rhetorical 
strategies to construct a narrative discourse in which women's narratives of sexual abuse are subsumed and suppressed, and how these female survivors use language for selfempowerment by constructing their narratives to challenge the dominant culture. A move from women's narratives of sexual abuse to television talk shows also shifts the emphasis from the textual space to a dramatic event. The shows seem to display openly a challenge to the suppression of dominant culture because the guests on the shows bring not only their own text to narrate but also their body into view. To investigate how the dramatic event of TV talk shows has changed the course of the power struggle between the dominant culture and a marginal group of female survivors, I will begin with Foucault's analysis of two political theatres: the theatre of terror and the theatre of discipline. The use of Foucault here is not only to support my discussion of sexual abuse but also to expose the limitations of his theories when set against personal experience of female survivors.

In Discipline and Punish, Michel Foucault opposes two political theatres: the 'theatre of terror' where power displays itself and the theatre of discipline where power disguises itself under the system of normalization. The first theatre takes place in what Foucault calls 'the spectacle of the scaffold' which dramatizes the exercise of power over the body of the condemned. Foucault says, 'by breaking the law, the offender has touched the very person of the prince-or at least those to whom he has delegated his forcewho seizes upon the body of the condemned man and displays it marked, beaten, broken' (Foucault, 1977: 49). Vision becomes a form of power that inscribes its invincible force on the body of the condemned. The spectacle of the scaffold therefore is meant to carry out the 'policy of terror': 'to make everyone aware, through the body of the criminal, of the unrestrained presence of the sovereign' (Foucault, 1977: 49).

More significantly, however, is Foucault's description of the spectacle of the scaffold as maintaining the characteristics of a game, a match or a duel. 'Torture,' says Foucault,' was a strict judicial game... Something of the joust survived between the judge who ordered the judicial torture and the suspect who was tortured' (Foucault, 1977: 40). In his discussion of Foucault, David Carroll notes:

In such a duel, power is exercised openly but in doing so it also risks itself. Battles, duels, and boxing matches are, in fact, sometimes, though not often, won by the less powerful, less well armed combatants. An upset is always within the realm of possibilities. When power is on display - as it is here - and exercised openly, it opens itself up the possibility that 'truth' may not end up being on its side (Carroll, 1987: 121).

Thus, Foucault says, where not enough evidence is available, the magistrate will not risk putting the accused to a physical trial 'for the rule was that if the accused 'held out' and did not confess, the magistrate was forced to drop the charges. The tortured man had then won' (Foucault, 1977: 40-41). 
Therefore, the traditional theatre is dramatic, spectacular but ineffectual. Power is put on display but at the risk of being directly challenged, subverted and overthrown. Beginning with the modern age, Foucault describes the exchange that took place in the following terms: 'The Shakespearean age when sovereignty confronted abomination in a single character had gone; the everyday melodrama of police power and of the complicities that crime formed with power was soon to begin' (Foucault, 1977: 283). The new penal system, in effect, introduced a modern theatre of discipline and surveillance. As such the game of power also changed its character: the new form of power 'seems all the less 'corporal' in that it is more subtly "physical" (Foucault, 1977: 177).

While the traditional theatre stages public torture and execution, it is the exercise of the power-knowledge regime that takes place in the modern theatre of discipline. Vision as a metaphor of knowledge is still linked with modern power but in a different way. Hubert L. Dreyfus and Paul Rabinow contrast the modern and the traditional forms of power in terms of visibility:

In traditional forms of power, like that of the sovereign, power itself is made visible, brought out into the open, put constantly on display. The multitudes are kept in the shadows, appearing only on the edges of power's brilliant glow. Disciplinary power reverses these relations. Now it is power itself which seeks invisibility and the objects of power--those on whom it operates--are made the most visible. It is this face of surveillance, constant visibility, which is the key to disciplinary technology (quoted in Zimmerman, 1990: 203).

Now the power to see, the power to make visible, is the power to control. Disciplinary power, unlike traditional power, is exercised through its invisibility while imposing compulsory visibility on its subjects. When power hides itself, when it engages us in asymmetrical relations, then we witness the age of terror in which the totality of power holds sway. No longer do we describe power relations in terms of a duel, a match or a battle. Rather we are subjected to the 'deployment of power' operating by means of arts and technology rather than violence and bloodshed.

Modern power, though less dramatic, is more subtle and more insidious in manipulating its subjects. According to Foucault, the Panopticon - an architectural design consisting of two parts: the centre, a tower and the peripheric building divided into cells - is a product of the technology of modern power. By virtue of its architectural and organizational innovation, the building forms a part of the disciplinary system. With this new technology of power, a direct confrontation between power and its opponents give way to an asymmetrical form of power relations. As Nancy Fraser puts it, 'the unidirectionality of visibility [created by the panoptical system] denied the inmates knowledge of when and whether they were actually being watched and thereby made them internalize the gaze and in effect surveil themselves' (Fraser, 1981: 277). The asymmetrical aspect of the 
panoptical gaze makes it possible for what Foucault calls 'the economy of punishment' - $\mathrm{a}$ form of penalties that is directed to the soul rather the body of the subject (Foucault, 1977: 95).

Foucault's discussion of the two theatres illustrates how power exercises its control over the subject by the play of difference: presence and absence, visibility and invisibility. Since vision as a metaphor of knowledge is linked with the power to control, Foucault's position against the metaphysics of presence inherited by modern society causes him to regard presence as a deployment of power. In the following analysis of the public confessions of female survivors in television programmes, I want to argue that women who want to politicize their narratives of sexual abuse need to insist on the politics of presence rather absence. In doing so, they need to revise the subject position which appears in Foucault's critique of presence so that it will no longer be considered as a passive individual but an active agent.

If Foucault argues that presence is promoted by modern power to put the subject under constant control and surveillance, this is not the case for female survivors who regard the absence of their voice and their bodies as a form of their powerlessness and victimization. According to Bass and Davis, among various effects reported by female victims of sexual abuse is a denial of their bodies. One survivor describes how she distances herself from her own body.

It's like I actually rise up out of my body. I could feel myself sitting in a chair, and I could feel myself floating up out of my body. That's exactly what it is, like being suspended in midair. I know. That my body is in the chair, but the rest of me is out of my body (Bass and Davis, 1988: 43).

Self denial is caused by the survivor's attitude towards her body as subjected to being controlled and victimized by the abuser. Although the victim's denial of her body is a strategy to distance herself from pain and suffering, that strategy, Bass and Davis argue, simply reinforces the survivor's conception of herself as a powerless victim. Bass and Davis include among the suggestions for survivors to overcome their victimization what they call 'listening to the body': the bringing back of the woman's body being attentive to her emotions and feelings. Mary McGrath, an incest survivor, insists on a rediscovery of the self as an important step in her healing process:

A big part of healing for me has been learning that I have power and options. I decided I didn't like not being responsible for my own life.... What I say to myself is 'I don't have to do anything, but I have to be open to my feeling and not shut down' (Bass and Davis, 1988: 445).

McGrath's description of her personal experience conveys a strong sense of authority and responsibility for her. Rather than distancing herself from her body, she has come to acknowledge her body as a source of power. A change of subject 
position, McGrath seems to suggest, must begin with a change in the survivor's attitude toward herself.

The survivor's acknowledgement of her body is usually accompanied by breaking the silence. In my analysis of survivor discourse concerning the issue, I expose a gap between Foucault's theories and the survivor's personal experience. Foucault's argument in his 'repressive hypothesis', that the relation between sex and power is not one of repression, links him with his critique of the modern theatre and its metaphysics of presence. Foucault says in his 'repressive hypothesis,' rather than repression, there has occurred a multiplicity of discourses concerning sex, an institutional incitement to speak about it and a responsibility, if not obligation, to tell oneself and significant others about their pleasures, thoughts or sensations that might have an affinity with sex (Foucault, 1990: 105-06). Since an incitement to tell the truth about one's self is regarded by Foucault as a deployment of power, Foucault's 'repressive hypothesis' seems allied with the dominant culture in the sense that it discourages female victims from speaking about their experience of sexual abuse. An anonymous survivor considers her silence as a form of her subordination to social injunction:

I feel very lonely and isolated. I've always had so much to say, and I've never said it. What's hindered me the most is being so skilled at being silent. Incest has had much to do with being silenced and silencing myself (Bass and Davis, 1988: 92).
In contrast with what Foucault says about 'repressive hypothesis,' Bass and Davis argue, 'an essential part of healing from child sexual abuse is telling the truth about one's life. The sexual molestation of children, and the shame that results, thrive on an atmosphere of silence. Breaking the silence is the most powerful healing tool' (Bass and Davis, 1988: 92).

It seems at this point that TV talk shows featuring first-person narratives of sexual abuse have been able, as Linda Alcoff and Laura Gray put it, 'to create new spaces within these discourses and to begin developing an autonomous counter discourse, one capable of empowering survivors' (Alcoff and Gray, 1993: 275). Indeed, my revision of Foucault's analysis of modern theatre and its metaphysics of presence makes it possible to see the presence of survivors and their accounts as a form of resistance to the repressive power. However, in doing so, I do not deny that the presence of survivors and their narratives on the shows is not subjected to being recuperated into dominant discourses. This will be seen in my following analysis of the relationship that exists between the host, the expert, the guest and the audience of the shows.

As in the modern theatre of discipline, the control of staged TV talk shows is carried out in a subtle insidious manner. The host of the show directs and controls the situation of the show basically through a discourse of language. Although the survivor as a guest of the show is allowed to speak, her narrative is preconditioned by the selected questions of the host. As such, the host takes control of the survivor's narratives and the 
audience's response to the issue. According to Alcoff and Gray, an instance of this happened in 'The Home Show' on BBC television in autumn 1990. Dana Fleming, one of the co-hosts of the show, asked Tracy, a rape survivor, to tell the audience 'what happened.' Alcoff and Gray say:

Tracy proceeded to outline her acquaintance rape, focusing on the normality of the situation prior to the assault. Her goal was to say something useful for other women who may be struggling with the aftermath of an assault and feeling as uncertain about what to do as she had felt. Fleming, however, wanted to focus on the violent act itself; she asked Tracy to explain to the audience whether she had done 'anything that in any way could have provoked him [the rapist]' (Alcoff and Gray, 1993: 275).

The survivor's freedom of speech was undercut by the conflict of her interest with that of the host. Fleming's question, Alcoff and Gray note, changed the course of the narrative and the intention of the guest by putting Tracy in a defensive position. Also the host's question affected the interpretation of the topic under discussion: it focused a discussion of rape on women's behaviour rather than men's responsibilities (Alcoff and Gray, 1993: 276).

In the shows an expert joins the host in directing the guest's narratives and interpreting their stories for the audience. The expert listens to the guest's accounts, gives suggestions and analyses the cases.
Alcoff and Gray explain the role of the expert in the show:

[The expert] almost invariably a white man or woman with a middle-class and professional experience, who, with a sympathetic but dispassionate air, explains the nature, symptoms and possible therapies for such crimes of violence. The survivors are reduced to victims, represented as pathetic objects who can only recount their experiences as if these are transparent, and who offer pitiable instantiation of the universal truths the experts reveal (Alcoff and Gray, 1993: 277).

The expert is not considered as a survivor's peer but rather as a specialist who possesses the scientific knowledge by which the story of the survivor is to be judged. The survivor has little opportunity to interpret her own story. It is the expert who imposes a theoretical framework upon the survivor's account and analyses the survivor's case in conformity with the standard of normalization. In doing so, the expert usually presupposes that there is something wrong, unusual and abnormal in the survivor's case and gives the survivor some suggestions for her readjustment. Also from another perspective, Alcoff and Gray say, 'these shows especially like victims with 'disorders,' such as multiple personalities, because this can expand opportunities for sensationalism and widen the emotional distance between the audience and the survivors, making it easier to objectify them as victims' (Alcoff and Gray, 1993: 277). Recuperation thus occurs when the show 
does not really intend to help the survivor but uses her account to promote public interest and sensationalism for commercial purposes.

The talk show programme shares some characteristics with the two political theatres described by Foucault. Although the TV talk show illustrates a move from the open struggle of crime and punishment to a safe anaesthetized distance made possible by modern technology, its capacity to resist, through diminished, has not been destroyed. As Alcoff and Gray note, 'the visual image of the survivor, although it can be used to objectify, has the potential to explode the stereotypes about who the survivors are as well as to encounter an invisibility that in the long run serves only to hide the true nature of patriarchy, which condones and promotes sexual violence' (Alcoff and Gray, 1993: 278). Similarly in Foucault's discussion of traditional theatre, the body of the condemned is an ambiguous site of subjugation to the invincible power of the sovereign and resistance to the inscription of that power. Also, Foucault argues the display of the body of the condemned either arouses the audience's pity and sympathy or their fear and hatred. The audience's ambiguous feelings often reverse the outcome of punishment: they may aid the sovereign in taking revenge on his enemies or take side with the victim in challenging the sovereign. Likewise in TV talk shows, the space between actors and spectators is resolved. Far from being silent witnesses, the audience are the main characters in the show. They participate in asking questions, give comments or criticisms, and take sides with or dismiss the victim.
Like the modern theatre, however, the talk show programme is more subtle in manipulating its subjects, including the audience and the guests of the show. Also, the host's and the expert's controlling and directing of the course of the show is basically the principle of knowledge and power that belongs to the modern theatre. Although the show allows confrontation between the survivor as a narrator and the expert as a listener, it is the latter who fabricates a discourse of knowledge to account for the survivor's story. Moreover, the expert's role as a distanced disinterested observer who categorizes, analyses and hierarchizes the survivor's case is similar to the panoptical Eye of disciplinary power. Foucault says, 'Instead of bending all its subjects into a single uniform mass, [the panoptical Eye] separates, analyses, differentiates, carries its procedures of decomposition to the point of necessary and sufficient single units' (Foucault, 1977: 170). Similar to the modern theatre, the TV talk show is aided by the technologies of production that form a part of its controlling system. Like the panoptical Eye, the gaze of camera as an apparatus hidden from the screen substitutes a unidirectional, asymmetrical form of relations for the open direct confrontation of the traditional theatre. The hidden gaze of the camera takes control of the viewers by framing their visual field. Alcoff and Gray note how the production of 'The Home Show' programme depends on camera techniques: to create the desired effect: 'Tracy [a rape victim] became an object of analysis and evaluation for experts and media-appointed representatives of the masses (Collins and Fleming [co-hosts]). The camera insistently cut away to Tracy's face even when others 
were speaking, as if to display the 'example' being discussed' (Alcoff and Gray, 1993: 276). The technical effect produced by the camera, together with the analysis of the expert and the host, shapes the production of the program.

\section{Conclusion}

In my discussion of sexual abuse, I have argued that the politics of discourse in narratives of sexual abuse is inseparable from the politics of location. Not only is sexual abuse a crime and violence that is directly inflicted upon the victim's body, it also illustrates how the problem of sexual inequality is always already located on a local level in the form of control over the body. Such awareness makes it possible for us to adapt the politics of everyday life to deal with the issue of sexual abuse.

Thus, I insist, for a survivor to initiate social change, she must begin not from the top but from the below, and not with any state agency but with herself and her body. I also point out that the survivor's breaking the silence is not just speaking out about sexual abuse but speaking in order to be heard by the public, to make them aware of the existence and the problem of sexual abuse. Therefore, a move from the private to public sphere is required for the survivor's narrative in order to effect a change in society. Usually, such a move brings into effect a revision of the dominant discourse to allow the survivor to speak about her experience of sexual abuse previously considered a taboo. However, as seen in the last part of my discussion, the survivor has to pay the price for her entry into the public realm. Given that power operates not only through exclusion and repression but also through the production and proliferation of discourses, as Foucault argues, the presence of the survivor's account in the public realm is subject to the recuperation of the dominant culture. However such a conception of power as illustrated by Foucault fails to account for the survivor's sense of agency and authority as a speaking subject in her narrative. It is the survivor's strategic use of language as a form of self empowerment that allows her to resist or challenge the dominant culture.

\section{References}

Alcoff, Linda and Gray, Laura. 1993.

Survivor Discourse: Transgression or Recuperation? Signs 18.2: 260-290.

Bass, Ellen and Davis, Laura. 1988. The Courage to Heal: A Guide for Women Survivors of Child Sexual Abuse. New York: Harper \& Row.

Carroll, David. 1987. Paraaesthetics: Foucault, Lyotard, Derrida. New York: Methuen.

Cornell, Drucilla. 1991. Beyond Accomodation: Ethical Feminism, Deconstruction and the Law. New York: Routledge.

Foucault, Michel. 1977. Discipline and Punish: The Birth of the Prison. Translated by Alan Sheridan. New York: Pantheon.

Foucault, Michel. 1990. History of Sexuality Volume 1: An Introduction. 
Translated by Robert Hurley. New York: Vintage.

Franser, Nancy. 1981. Foucault on Modern Power: Empirical Insights and Normative Confusions. Praxis International 1.3: 272-87.

Gallagher, Vera. 1985. Speaking Out, Fighting Back. Seattle: Madrona.

hooks, bell. 1989. Talking Back.Boston: South End.

McNaron, Toni and Yarrow Morgan. 1982. Voices in the Night: Women Speaking about Incest. San Francisco: Cleis Press.

Ryan, Michael. 1989.Politics and Culture: Working Hypotheses for a PostRevolutionary Society. Baltimore: John Hopkins University Press.

Silverman, Kaja. 1983. The Subject of Semiotics. New York: Oxford University Press.

Zimmerman, Michael E. 1990. Heidegger's Confrontation with Modernity. Bloomington: Indiana University Press. 